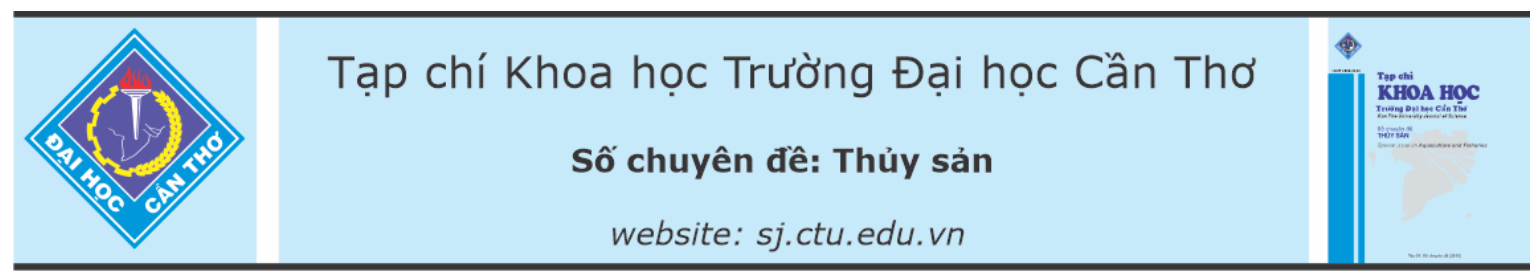

DOI:10.22144/ctu.jvn.2021.072

\title{
CHÂT LỰ̛̣G NƯỚC TRONG KHU VỰC NUÔI TÔM TỈNH BẠC LIÊU
}

\author{
Trần Trung Giang*, Âu Văn Hóa, Trương Quốc Phú, Vũ Ngọc Út và Huỳnh Trường Giang \\ Khoa Thủy sản, Truò̀ng Đại học Cần Tho \\ *Người chịu trách nhiệm về bài viết: Trần Trung Giang (email: trunggiang@ctu.edu.vn)
}

\section{Thông tin chung:}

Ngày nhận bài: 22/02/2021

Ngày nhận bài sủa: 02/04/2021

Ngày duyệt đăng: 01/06/2021

Title:

Surface water quality in the intensive shrimp culture area of Bac Lieu province

\section{Tù khóa:}

Bạc Liêu, chất luợng nuoóc, cưa sông, tôm nuớc lơ

\section{Keywords:}

Bac Lieu, estuary, shrimp culture, water quality

\begin{abstract}
With a view to becoming the national shrimp capital, authorities in Bac Lieu has oriented the development and applications of science and technology in shrimp industry. Bac Lieu province is known as a one of the most developed aquaculture areas in the Mekong Delta region with various systems such as semi-intensive, intensive, and super-intensive shrimp farming. Therefore, the aim of this study was to assess the quality of water supply resources surrounding shrimp culture ponds to provide fundamental understanding about the spatial and seasonal variations of water quality in Bac Lieu where the shrimp culture has been intensified. Water samples were monthly collected at 5 sites in key features of estuaries in the shrimp culture area of the province over a year. Results showed that the water quality in the shrimp farming area is fewer fluctuations, still qualified the requirements of the national standards, and suitable as water supply for shrimp culture in the research area. However, it could be noted that concentrations of TSS, $\mathrm{H}_{2} \mathrm{~S}$, and $\mathrm{PO}_{4}{ }^{3-}$ were relatively high compared to the standards for marine shrimp. Considering the BLI (Nha Mat estuary - Bac Lieu city) and BL5 (Ganh Hao estuary - Dong Hai) sites, most water quality parameters were highly fluctuated among the seasons. Additionally, poor water quality occurred in the dry and dry-rainy seasons at the Ganh Hao estuary (site BL5).
\end{abstract}

\section{TÓM TẮT}

Nhằm huớng tới trở thành thủ phủ tôm của cả nước, Bạc Liêu đã định huớng phát triển, úng dụng khoa học kỹ thuật đối với nền công nghiệp này. Bạc liêu được biết đến nhu là một trong nhũ̃ng tỉnh có hoạt động nuôi tôm phát triển ở đồng bằng sông Cưu Long với các mô hình nuôi khác nhau nhu là bán thâm canh, thâm canh và siêu thâm canh. Vì vậy, mục tiêu của nghiên cưu này là đánh giá sự biến động chất lượng nuớc theo không gian và thời gian nhằm cung cấp thông tin cho người nuôi trong việc quản lý chất lượng nước trong quá trình nuôi. Mẫu nuớc tầng mặt được thu hàng tháng tại 5 diểm ở các cưa sông trọng yếu trong khu vực nuôi tôm của tỉnh trong suốt 1 năm. Kết quả cho thấy chất lượng nước tụ nhiên tại khu vực nuôi it bị biến động, đạt yêu cầu theo các quy chuẩn về chất luợng nước tầng mặt, phù hợp đối với việc sủ dụng nguồn nước phục vu cho nhu cầu nuôi trồng thủy sản của vùng, đặc biệt là nghề nuôi tôm nước lợ. Riêng hàm luợng vật chất lo lưng TSS, $\mathrm{H}_{2} \mathrm{~S}$ và $\mathrm{PO}_{4}{ }^{3-}$ trong nước tại một số điểm thu khá cao so với một số quy chuẩn về quản lý chất luợng nước. Hầu hết các yếu tố chất luợng nuớc tại các điểm thu BL1 (sông Nhà Mát - TP. Bạc Liêu) và BL5 (cưa sông Gành Hào - Đông Hải) rất biến động theo mùa. Hơn nũa chất lương nước có khuynh hướng kém vào mùa khô và giao mùa khô-mua tại vùng cưa sông Đông Hải (BL5). 


\section{GIỚI THIÊU}

Bạc Liêu có đường bờ biển khoảng $56 \mathrm{~km}$, kéo dài từ thành phố Bạc Liêu đến các huyện Hòa Bình, Đông Hải với hệ thống sông ngòi chằng chịt, nên việc dẫn nước mặn về nội đồng rất thuận tiện. Chính vì thế, nghề nuôi trồng thủy sản ở Bạc Liêu phát triển mạnh và là vùng nuôi thủy sản có diện tích nuôi tôm thâm canh - bán thâm canh và siêu thâm canh lớn. Hiện nay, Bạc Liêu được giao nhiệm vụ tập trung mở rộng diện tích và tăng sản lượng tôm nuôi trong thời gian tới. Theo Sở Nông nghiệp và Phát triển nông thôn tỉnh Bạc Liêu (2019), tỉnh hiện có hơn 135 ngàn ha diện tích nuôi tôm, đứng thứ 2 cả nước với sản lượng tôm năm sau luôn cao hơn năm trước, sản lượng năm 2019 đạt 155 ngàn tấn. Tỉnh Bạc Liêu hiện có 188 cơ sở sản xuất tôm giống và 108 cơ sở ương dưỡng tôm giống, hàng năm sản xuất khoảng 30 tỷ con giống. Đặc biệt, Bạc Liêu có nhiều mô hình tôm đa dạng, hiệu quả cao, nhất là các mô hình nuôi thâm canh, siêu thâm canh ứng dụng khoa học công nghệ cao, tiên tiến hàng đầu (Bộ Nông nghiệp và Phát triển Nông thôn, 2015). Với mục tiêu hướng tới trở thành thủ phủ tôm của cả nước, tiến tới xây dựng thương hiệu tôm Việt Nam, Bạc Liêu đã định hướng phát triển nông nghiệp gắn với ứng dụng khoa học kỹ thuật trong sản xuất. Tỉnh đã phê duyệt đề án "Tái cơ cấu ngành thủy sản tỉnh Bạc Liêu đến năm 2020, định hướng đến năm 2030 theo hướng nâng cao giá trị gia tăng và phát triển bền vững". Theo đó, Bạc Liêu sẽ xây dựng cơ sở hạ tầng đồng bộ về điện, đường giao thông, cấp thoát nước, xây dựng cơ sở hạ tầng vùng sản xuất con giống tập trung để thu hút doanh nghiệp, qua đó góp phần nâng cao thu nhập và cải thiện mức sống cho cộng đồng ngư dân ven biển (Bộ Nông nghiệp và Phát triển Nông thôn, 2015; Trung tâm Khuyến nông Bạc Liêu, 2020).

Tuy nhiên, việc đầu tư nuôi tôm với diện tích lớn và luôn mở rộng, thêm vào đó là việc nuôi tôm với các mô hình công nghiệp quy mô lớn sẽ có những ảnh hưởng không nhỏ đến nguồn tài nguyên thiên nhiên của vùng, đặc biệt là nguồn nước. Trong đó có cả hai nguồn là nguồn nước cung cấp và nguồn nước xả thải sau khi sử dụng trong nuôi trồng thủy sản. Việc nuôi tôm với mật độ cao với các vụ nuôi liên tục không nghỉ sẽ ảnh hưởng và tác động rất lớn đến nguồn nước trong khu vực thông qua việc lấy nguồn nước và xử lý khi xả thải ra bên ngoài môi trường tự nhiên. Bên cạnh đó, các ao nuôi hay khu vực nuôi tôm luôn kề sát nhau và sử dụng nguồn nước chung kênh dẫn cũng là một trong những nguyên nhân dẫn đến dịch bệnh dễ dàng bùng phát và rất khó quản lý trong khu vực. Hơn nữa, việc xử lý khối lượng chất thải trong hoạt động nuôi tôm thâm canh và bán thâm canh trên địa bàn cũng là một vấn đề cần được quan tâm và giải quyết. Song song đó, thời tiết hiện nay có những chuyển biến không theo quy luật và rất khó có thể dự báo. Việc biến đổi khí hậu, mực nước biển dâng và sự xâm nhập mặn liên tục đã và đang diễn ra tác động trực tiếp đến nguồn nước cấp của vùng vì vị trí khu vực nuôi tôm trên địa bàn tỉnh hầu như tiếp giáp với biển. Đặc biệt là các kênh dẫn, thủy vực vùng cửa sông dẫn nước từ biển vào cho khu vực nuôi khi triều cao cũng như trao đổi nguồn nước từ nội đồng đổ ra để trao đổi với biển khi triều thấp. Việc theo dõi sự thay đổi chất lượng nguồn nước và biến động trong khu vực là hết sức cần thiết vì nó tác động trực tiếp đến nghề nuôi trồng thủy sản của vùng, ảnh hưởng đến thu nhập của người dân cũng như có tác động rất lớn đến các doanh nghiệp, công ty đang nuôi tôm trong khu vực. Nghề nuôi trồng thủy sản của vùng không chỉ ảnh hưởng đến người nuôii, các công ty, doanh nghiệp mà còn ảnh hưởng đến nền kinh tế của tỉnh nói riêng và cả nước nói chung. Chính vì vậy, việc quản lý, theo dõi nguồn nước phục vụ cho nghề nuôi trồng thủy sản trong khu vực được đảm bảo là hết sức cần thiết và phải được chú trọng. Bên cạnh đó, việc nâng cao nhận thức của các tổ chức, cá nhân hoặc những vấn đề tác động về môi trường nước cần được quan tâm và phổ biến rộng khắp để mọi người chung tay, giúp sức trong giai đoạn hiện nay nhằm hướng đến sự phát triển bền vững của vùng nói chung và nghề nuôi trồng thủy sản nói riêng.

Vì vậy, nghiên cứu và tìm hiểu về diễn biến chất lượng nước tầng mặt trong tự nhiên của khu vực nuôi tôm tỉnh Bạc Liêu qua các mùa là cần thiết. Kết quả nghiên cứu sẽ đưa ra những nhận định, cảnh báo để có biện pháp quản lý, xử lý phù hợp về thay đổi chất lượng nước để phục vụ cho việc nuôi trồng thủy sản và tài nguyên nước trong khu vực.

\section{VẬT LIẾU VÀ PHƯƠNG PHÁP NGHIẾN CÚU}

\subsection{Thời gian và địa điểm thu mẫu}

Mẫu nước tầng mặt được thu tại 5 điểm ở các cửa sông dọc theo tuyến đê biển trải dài từ thành phố Bạc Liêu đến cửa sông Gành Hào, huyện Đông Hải, tiếp giáp với tỉnh Cà Mau. Các điểm thu được chọn tại các cửa sông dẫn nước vào các khu vực nuôi tôm chịu ảnh hưởng bởi nguồn nước biển và nguồn nước dẫn từ nội đồng của khu vực nuôi tôm.

Các vị trí thu mẫu là ngay các cửa sông có lưu lượng lớn và trao đổi nước liên tục, dòng triều biến 
thiên theo chu kỳ ngày đêm và có diện tích nuôi tôm phía trong nội đồng rộng lớn của khu vực. Mẫu nước được thu mỗi tháng 1 lần, vào tuần đầu tiên của tháng. Thời gian thu mẫu vào buổi sáng, lúc nước lớn trong ngày.

Bảng 1. Các điểm thu mẫu tại khu vực nuôi tôm tỉnh Bạc Liêu

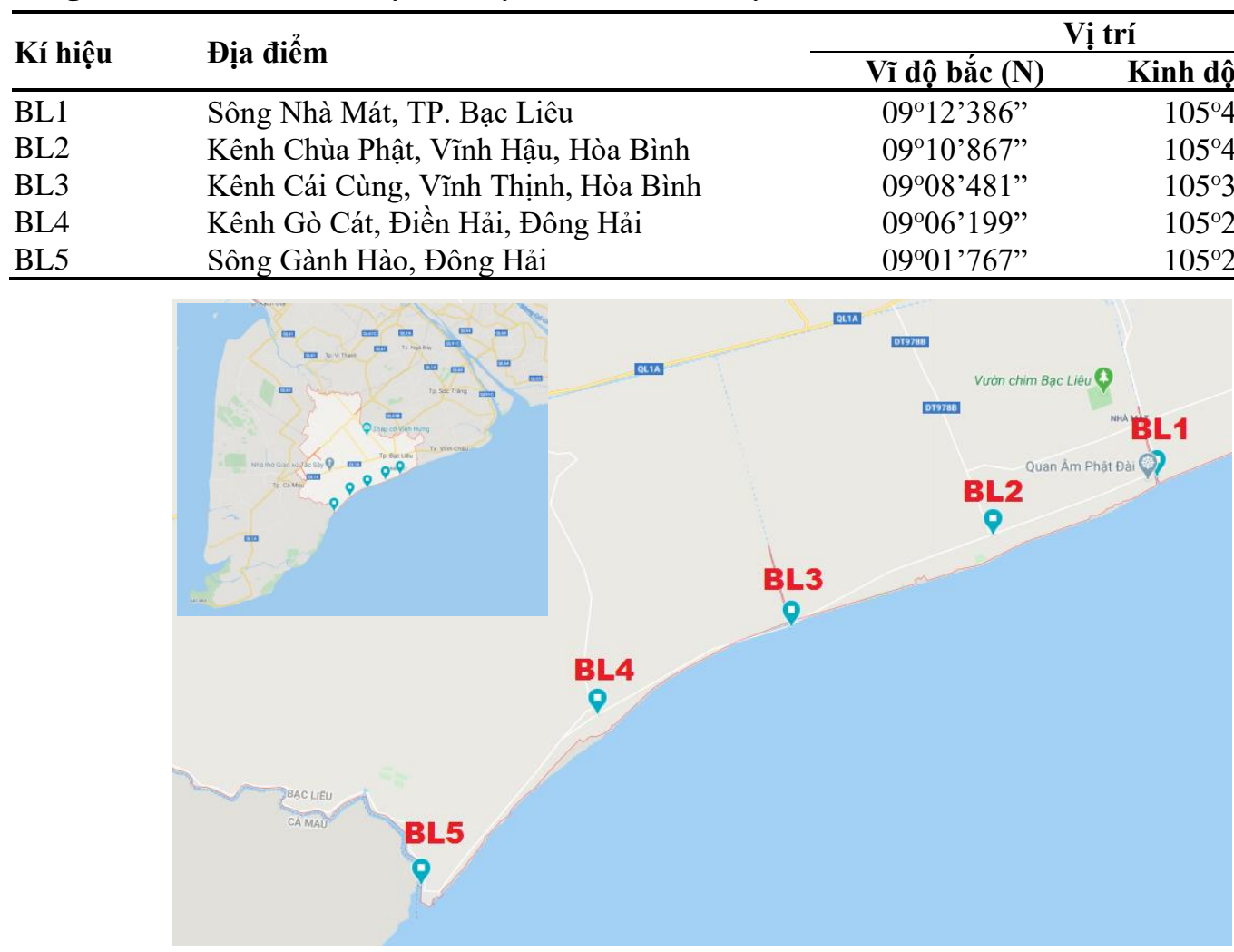

Hình 1: Các điểm thu mẫu tại khu vực nuôi tôm tỉnh Bạc Liêu

\subsection{Phương pháp thu và phân tích mẫu}

Mẫu nước được thu vào buổi sáng, đại diện cho thủy vực tại các điểm thu và vận chuyển về phòng thí nghiệm để phân tích. Các chỉ tiêu theo dõi được phân tích tại phòng Thí nghiệm Phân tích chất lượng nước, Bộ môn Thủy sinh học ứng dụng, Khoa Thủy sản, Trường Đại học Cần Thơ. Phương pháp thu mẫu và phân tích dựa theo chuẩn APHA (1995) (Bảng 2).

\section{Bảng 2. Phương pháp thu, bảo quản và phân tích mẫu}

\begin{tabular}{|c|c|c|}
\hline Chỉ tiêu & Phương pháp thu mẫu & Phương pháp phân tích \\
\hline Nhiệt độ & Đo trực tiếp & Máy đo đa chỉ tiêu HANNA (HI9828) \\
\hline $\mathrm{pH}$ & Đo trực tiếp & Máy đo đa chỉ tiêu HANNA (HI9828) \\
\hline Độ mặn & Đo trực tiếp & Máy đo đa chỉ tiêu HANNA (HI9828) \\
\hline DO & $\mathrm{MnSO}_{4}$ và $\mathrm{KI}-\mathrm{NaOH}$ & 5210-DO-B. Winkler Method (APHA, 1995) \\
\hline TSS & Trữ lạnh $\left(4^{\circ} \mathrm{C}\right)$ & 2540-TSS-D. Total Suppended Solid (APHA, 1995) \\
\hline Độ kiềm & Trữ lạnh $\left(4^{\circ} \mathrm{C}\right)$ & 2320-Alkalinity-B. Acid Method (APHA, 1995) \\
\hline $\mathrm{BOD}_{5}$ & $\mathrm{MnSO}_{4}$ và $\mathrm{KI}-\mathrm{NaOH}$ & 5210-DO-B. Winkler Method (APHA, 1995) \\
\hline COD & Cố định dd $\mathrm{H}_{2} \mathrm{SO}_{4}$ & 5220-COD-C. Dicromate Method (APHA, 1995) \\
\hline TAN & Trữ lạnh $\left(4^{\circ} \mathrm{C}\right)$ & 4500-NH3 $-\mathrm{F}$. Phenate Method (APHA, 1995) \\
\hline $\mathrm{NO}_{2}{ }^{-}$ & Trữ lạnh $\left(4^{\circ} \mathrm{C}\right)$ & 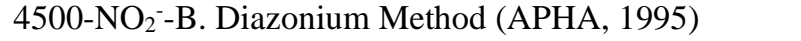 \\
\hline $\mathrm{H}_{2} \mathrm{~S}$ & Trữ lạnh $\left(4^{\circ} \mathrm{C}\right)$ & 4500-S-D. Methylene Blue Method, (APHA, 1995) \\
\hline $\mathrm{PO}_{4}^{3-}$ & Trữ lạnh $\left(4^{\circ} \mathrm{C}\right)$ & 4500- $\mathrm{PO}_{4}{ }^{3-}$-D. Stannous chloride Method (APHA, 1995) \\
\hline
\end{tabular}




\subsection{Xử lý số liệu}

Số liệu được ghi nhận và xử lý qua các đợt thu mẫu bằng phần mềm Microsoft Excel. Các thông số môi trường nước tại các điểm thu cũng được so sánh, đánh giá sự biến đổi của các thông số môi trường nước giữa các thủy vực trong cùng một đợt thu mẫu hoặc giữa các đợt thu mẫu theo các mùa khác nhau: mùa khô (tháng 12-3), giao mùa khô-mưa (tháng 45), mùa mưa (tháng 6-9) và giao mùa mưa-khô (tháng 10-11). Các thông số phân tích được so sánh và nhận định dựa theo các quy chuẩn kỹ thuật quốc gia về chất lượng nguồn nước cũng như các chỉ số quy định dùng trong nuôi trồng thủy sản, nuôi tôm nước lợ mặn để đánh giá.

\section{KẾT QUẢ VÀ THẢO LUẬN}

\subsection{Nhiệt độ và $\mathbf{p H}$}

Nhiệt độ tại các điểm thu dọc theo đê biển khu vực nuôi tôm có giá trị từ $29,2-31,8^{\circ} \mathrm{C}$ qua các thời điểm thu mẫu. Kết quả ghi nhận cho thấy nhiệt độ nước có xu hướng dao động tương đồng với nhiệt độ của vùng khí hậu gió mùa xích đạo. Nhiệt độ có giá trị trung bình cao nhất ở khí hậu giao mùa khô-mưa và giảm thấp vào mùa mưa. Giá trị nhiệt độ trung bình cao nhất là $31,8 \pm 1,1^{\circ} \mathrm{C}$ ở điểm thu $\mathrm{BL} 3$ và thấp nhất là $30,7 \pm 0,5^{\circ} \mathrm{C}$ ở điểm thu $\mathrm{BL} 5$ vào giao mùa khô-mưa. Vào mùa mưa, nhiệt độ giảm thấp nhất ở điểm thu BL4 với giá trị trung bình là $29,2 \pm 1,6^{\circ} \mathrm{C}$.

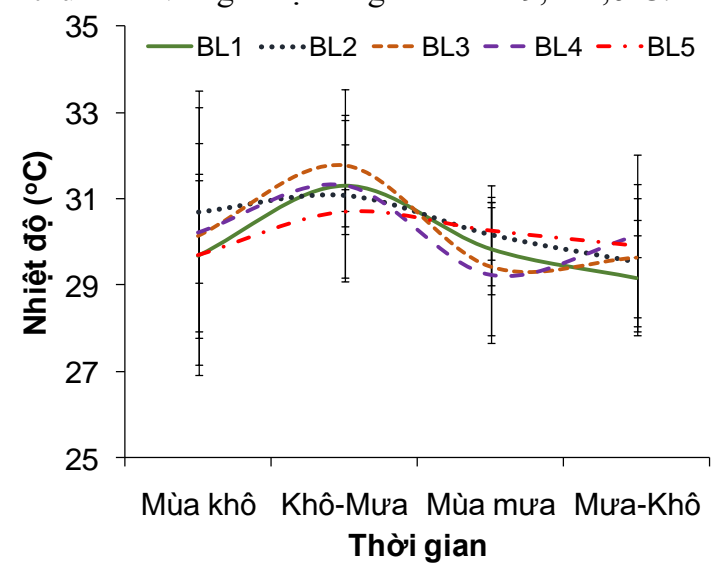

Theo Trần Trung Giang và ctv. (2020) ghi nhận nhiệt độ tại các điểm thu dọc tuyến Sông Mỹ Thanh có giá trị nhiệt độ dao động $27,2-32,6^{\circ} \mathrm{C}$ từ tháng 1 đến tháng 6 trong năm. Theo kết quả quan trắc tại các huyện trọng điểm nuôi tôm của tỉnh Sóc Trăng trong tháng 5 năm 2019, nhiệt độ nước ở khu vực nuôi tôm tại 4 huyện Mỹ Xuyên, Trần Đề, Cù Lao Dung và Vĩnh Châu dao động từ $30,0-32,2^{\circ} \mathrm{C}$ (Tổng cục Thủy sản, 2019). Kết quả cho thấy nhiệt độ nước tầng mặt tại các cửa sông có giá trị gần ngang nhau, ít dao động và biến động theo mùa.

Kết quả ghi nhận giá trị pH ở các điểm thu ít biến động qua các mùa thu mẫu cũng như tại các điểm thu mẫu. Giá trị pH trung bình từ 7,9-8,3 ở các điểm thu và không chênh lệch giữa các điểm cũng như qua các mùa thu mẫu. Riêng điểm thu BL5 tuy giá trị $\mathrm{pH}$ không biến động tương đồng theo các điểm thu khác là do điểm thu này là vùng cửa sông lớn nhất so với các điểm thu còn lại, lưu lượng nước lớn, diện tích rộng nên giá trị pH ít bị biến đổi qua các mùa thu mẫu. Giá trị $\mathrm{pH}$ tại các điểm qua thời gian thu mẫu vẫn trong giới hạn $(6,5-8,5)$ vùng nuôi trồng thủy sản, chất lượng nước biển vùng biển ven bờ theo QCVN 10-MT:2015/BTNMT (Bộ Tài nguyên và Môi trường, 2015b) và phù hợp với $\mathrm{QCVN} 08$ MT:2015/BTNMT (A1: 6,0-8,5) (Bộ Tài nguyên và Môi trường, 2015a).

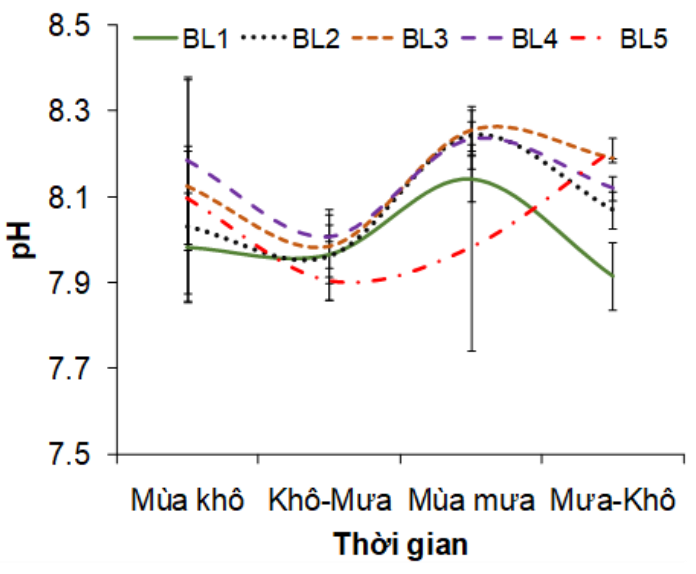

\section{2. Độ mặn và TSS}

Độ mặn của nước ghi nhận được có giá trị trung bình thấp nhất là $14,2 \%$ và trung bình cao nhất là $22,5 \%$ tại các điểm qua thời gian thu mẫu. Kết quả ghi nhận độ mặn có xu hướng tăng cao sau mùa khô và tăng cao nhất vào thời gian giao mùa khô-mưa. Thời gian sau, giá trị độ mặn giảm dần vào mùa mưa và giao mùa mưa-khô. Điều này cũng dễ thấy rõ sự thay đổi độ mặn theo mùa trong năm. Do vào mùa khô, nước trong nội đồng đổ ra kém, nước biển xâm nhập sâu vào nội đồng nên độ mặn tăng cao và vào mùa mưa, lượng nước ngọt từ nội đồng đổ ra biển nhiều hơn nên độ mặn tại điểm thu các vùng cửa sông có xu hướng giảm thấp. Kết quả cũng ghi nhận độ mặn tại các cửa sông ít biến động tại các điểm thu và có $x u$ hướng tương tự nhau. Riêng tại điểm thu BL5, do đây là cửa sông lớn nên vào mùa mưa 
lượng nước ngọt từ nội đồng đổ ra nhiều hơn làm cho độ mặn tại đây giảm thấp vào mùa mưa và thời điểm giao mùa mưa khô. Kết quả ghi nhận độ mặn tại điểm thu BL5 có giá trị trung bình là $15,4 \pm 9,7 \%$ o vào mùa mưa và đạt $16,7 \pm 4,3 \%$ vào thời điểm giao mùa mưa-khô. Đối với các cửa sông tiếp giáp với biển, hiện tượng xâm nhập mặn từ biển vào các sông xảy ra khá phổ biến, đặc biệt vào mùa khô. Khi đó lượng nước từ sông đổ ra biển giảm, thủy triều từ biển sẽ mang nước mặn lấn sâu vào lòng sông làm cho dòng sông bị xâm nhập mặn. Độ mặn sẽ giảm dần khi càng tiến sâu vào nội đồng. Theo tính toán và dự báo xâm nhập mặn tỉnh Bạc Liêu theo kịch bản biến đổi khí hậu của Nguyễn Kỳ Phùng và ctv. (2016) đã ghi nhận được độ mặn tại cửa sông Gành Hào vào tháng 3 năm 2010 dao động từ 21-26\%. Theo nhận định của Bộ Khoa học và Công nghệ (2016), tại cửa sông, độ mặn cũng có chu kỳ hàng ngày, chu kỳ 15 ngày và chu kỳ hàng tháng tương tự như chu kỳ của thủy triều. Do ảnh hưởng bởi các yếu tố khí tượng, trong tháng 2-3 mực nước đỉnh

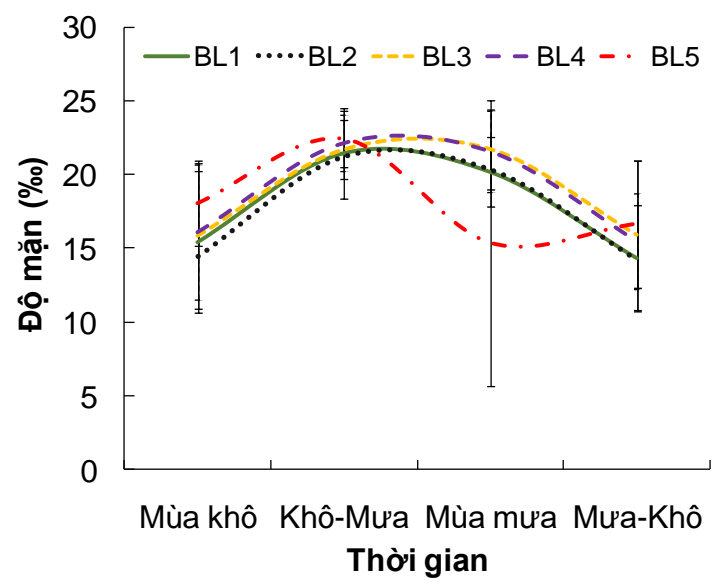

triều gia tăng đến 20-30 cm, dẫn tới độ mặn cũng gia tăng theo. Vùng Bán đảo Cà Mau (bao gồm vùng biển Bạc Liêu) có diễn biến độ mặn trong khu vực khá phức tạp, độ mặn lớn nhất trong thời kỳ quan trắc lớn nhất xuất hiện chủ yếu vào tháng 4 hoặc tháng 5 trong năm (giao mùa khô-mưa), chậm hơn so với các khu vực khác. Vào mùa khô cũng như thời điểm giao mùa khô-mưa, với sự suy giảm của lưu lượng dòng chảy từ thượng lưu đổ về, độ mặn cũng tăng lên và đạt giá trị lớn nhất vào giai đoạn triều cường và dòng chảy thượng nguồn nhỏ nhất. Tại vùng Đồng bằng sông Cửu Long cũng như vùng bán đảo Cà Mau, dòng chảy sông Mê Kông chảy vào thời điểm này thường kém nên việc xâm nhập mặn thường hay xảy ra. Viện Khoa học Thủy lợi (2013) báo cáo về việc dự báo xâm nhập mặn tại các cửa sông vùng ven biển Đồng bằng sông Cửu Long và đề xuất các giải pháp chống hạn thì tại cửa sông Gành Hào tỉnh Bạc Liêu có độ mặn cao vào kỳ triều cường cuối tháng $2 / 2013$ với độ mặn lớn nhất tháng đạt 27,4\%o.

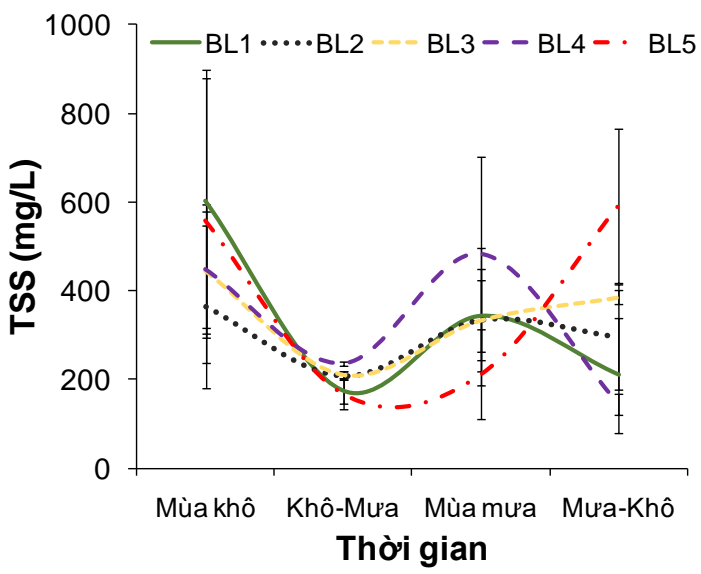

Hình 3. Độ mặn và TSS qua thời gian thu mẫu

Kết quả ghi nhận tổng chất rắn lơ lửng có giá trị rất lớn qua thời gian thu mẫu. Hàm lượng đạt giá trị trung bình từ $143,0-602,5 \mathrm{mg} / \mathrm{L}$ tại các điểm thu. Tổng chất rắn lơ lửng có xu hướng giảm vào thời điểm giao mùa khô-mưa và biến động cao vào các thời điểm còn lại trong năm. Điều này cho thấy rằng dòng triều cũng như lưu lượng nước ảnh hưởng rất lớn đến hàm lượng chất rắn lơ lửng trong nước. Đối với các cửa sông tiếp giáp với biển, hiện tượng xâm nhập mặn từ biển vào các sông xảy ra khá phổ biến, đặc biệt vào mùa khô. Khi đó lượng nước từ sông đổ ra biển giảm, thủy triều từ biển sẽ mang nước mặn lấn sâu vào lòng sông. Kết quả là vào thời điểm giao mùa khô-mưa, nước biển dâng cao và đi sâu vào nội địa làm độ mặn tăng. Bên cạnh đó, nước biển với trữ lượng lớn hơn đã làm cho hàm lượng tổng chất rắn lơ lửng trong nước tại các cửa sông có khuynh hướng giảm. Theo giá trị giới hạn của tổng chất rắn lơ lửng trong nước mặt dùng cho mục đích bảo vệ đời sống thủy sinh vật được quy định theo QCVN 38:2011/BTNMT thì có giá trị là $100 \mathrm{mg} / \mathrm{L}$ (Bộ Tài nguyên và Môi trường, 2011). So với kết quả ghi nhận hiện tại thì tổng chất rắn lơ lửng trong nước tại các điểm thu có giá trị cao từ 1,4-6,0 lần so với quy chuẩn. Theo quy chuẩn giới hạn của các thông số chất lượng nước biển vùng biển ven bờ (QCVN 10MT:2015/BTNMT), tổng chất rắn lơ lửng của vùng nuôi trồng thủy sản, bảo tồn thủy sinh vật thì chất lượng nước biển vùng biển ven bờ có giá trị giới hạn là $50 \mathrm{mg} / \mathrm{L}$ (Bộ Tài nguyên và Môi trường, 2015b). Theo kết quả quan trắc môi trường chất lượng nước phục vụ vùng nuôi tôm nước lợ tỉnh Cà Mau của 
Tổng cục Thủy sản năm 2018, tổng chất rắn lơ lửng tại 5 điểm quan trắc trên các tuyến sông thuộc địa bàn tỉnh Cà Mau có hàm lượng từ 153-463 mg/L, vượt ngưỡng cho phép từ 1,53-4,63 lần. Theo quan sát, hàm lượng vật chất lơ lửng trong nước chủ yếu là phù sa, keo khoáng nên hàm lượng vật chất lơ lửng có giá trị cao, đây là đặc trưng thông thường của các sông phù sa tại vùng Đồng bằng sông Cửu Long. Hơn nữa, điểm thu là các thủy vực vùng cửa sông lớn, chịu sự tác động của dòng chảy, thủy triều; đây là các kênh dẫn chính từ nội đồng chịu ảnh hưởng của khu vực nuôi tôm trong vùng nên hàm lượng tổng chất rắn lơ lửng biến động và có hàm lượng khá cao quanh năm.

\subsection{Hàm lượng oxy hòa tan (DO) và độ kiềm}

Hàm lượng oxy hòa tan ở 5 cửa sông lớn dọc tuyến đê biển Bạc Liêu có hàm lượng khá cao và ít biến động qua các mùa thu mẫu. Hàm lượng oxy hòa tan ở các cửa sông dao động từ 4,0-5,6 mg/L, trung bình là $4,9 \pm 0,4 \mathrm{mg} / \mathrm{L}$. Do đây là các thủy vực nước chảy, có lưu lượng nước lớn, tốc độ dòng chảy mạnh và liên tục chịu sự tác động của sóng, gió, dòng triều nên hàm lượng oxy hòa tan trong nước khá cao. Theo QCVN 02-19:2014/BNNPTNT, chất lượng

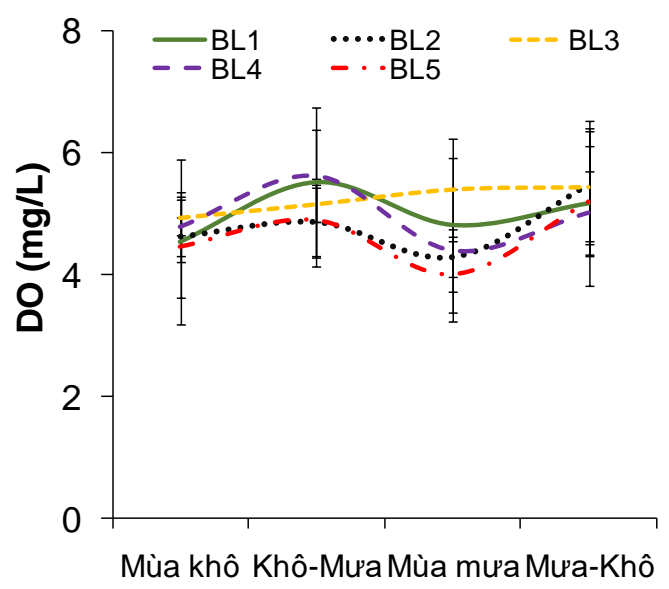

Thời gian nước cấp vào ao nuôi và nước ao nuôi tôm sú và tôm thẻ chân trắng có giá trị oxy hòa tan phải lớn hơn 3,5 $\mathrm{mg} / \mathrm{L}$ (Bộ Nông nghiệp và Phát triển nông thôn, 2014). Đối với vùng nuôi trồng thủy sản, bảo tồn thủy sinh vật chất lượng nước biển vùng biển ven bờ theo QCVN 10-MT:2015/BTNMT quy định giá trị hàm lượng oxy hòa tan phải lớn hơn $5,0 \mathrm{mg} / \mathrm{L}$ (Bộ Tài nguyên và Môi trường, 2015b). Theo đề xuất của Boy \& Green (2002), hàm lượng oxy hòa tan trong nước để nuôi tôm nước lợ vào khoảng 5,0-6,0 $\mathrm{mg} / \mathrm{L}$. Như vậy có thể thấy rằng, hàm lượng oxy hòa tan ở nghiên cứu hiện tại phù hợp với việc phục vụ cho nuôi tôm nước lợ của vùng. Theo Trần Trung Giang và ctv. (2020), hàm lượng oxy hòa tan trung bình ở các điểm thu dọc tuyến sông Mỹ Thanh, Sóc Trăng qua 6 tháng thu mẫu có giá trị trung bình là $4,4 \pm 0,3 \mathrm{mg} / \mathrm{L}$. Theo báo cáo của Tổng cục Thủy sản (2019) khi quan trắc môi trường tại các huyện trọng điểm nuôi tôm tỉnh Sóc Trăng trong tháng 5 năm 2019, hàm lượng oxy hòa tan ở Trần Đề và Cù Lao Dung của tỉnh Sóc Trăng có hàm lượng oxy trong ngưỡng từ $3,5-4,7 \mathrm{mg} / \mathrm{L}$. Như vậy có thể thấy rằng ở các thủy vực tự nhiên, đặc biệt là các vùng thủy vực cửa sông thì có hàm lượng oxy hòa tan trong nước khá cao.



Thời gian

\section{Hình 4. Hàm oxy hòa tan và độ kiềm qua thời gian thu mẫu}

Độ kiềm ở 5 điểm qua các mùa thu mẫu ít có sự biến động và dao động $89,1-128,0 \mathrm{mgCaCO}_{3} / \mathrm{L}$. Do đây là các thủy vực vùng cửa sông, nơi giao thoa của nước biển và nước sông nội đồng đổ ra từ khu vực nuôi tôm của vùng nên hàm lượng độ kiềm khá cao và ít biến động. Độ kiềm có vai trò quan trọng trong ao nuôi tôm vì giúp hỗ trợ trong quá trình lột xác của tôm. Độ kiềm trong nước thấp có thể làm biến động $\mathrm{pH}$, giảm tăng trưởng và tăng tỷ lệ chết ở tôm. Độ kiềm trong nước quá cao có thể làm giảm lượng muối khoáng trong nước gây rối loạn quá trình lột xác tôm. Trần Trung Giang và ctv. (2020) cho rằng đối với thủy vực vùng cửa sông và các điểm thu ở thủy vực sông nhánh khu vực nuôi tôm tỉnh Sóc Trăng có giá trị từ $91,1 \pm 8,4 \mathrm{mgCaCO}_{3} / \mathrm{L}$ đến $103,6 \pm 17,1 \mathrm{mgCaCO}_{3} / \mathrm{L}$ tương ứng. Theo nghiên cứu của Venkateswarlu et al. (2019), độ kiềm trong ao nuôi tôm thẻ chân trắng $L$. vannamei có giá trị 
trung bình từ $137 \pm 41,5 \mathrm{mgCaCO}_{3} / \mathrm{L}$ đến $146 \pm 16,5$ $\mathrm{mgCaCO}_{3} / \mathrm{L}$ ở các ao nuôi tôm bán thâm canh của hệ thống nuôi trồng thủy sản nước lợ tại Andhra Pradesh, Ân Độ. Theo Boyd (1998), độ kiềm thích hợp cho tôm nước lợ có giá trị lớn hơn 80 $\mathrm{mgCaCO}_{3} / \mathrm{L}$. Nhìn chung, độ kiềm trong nước tại các điểm thu khá ổn định qua các mùa và có hàm lượng tương thích cho việc dùng nguồn nước phục vụ cho nuôi trồng thủy sản, đặc biệt là vùng nuôi tôm nước lợ trong khu vực.

\section{4. $B O D 5$ và $C O D$}

Nhu cầu oxy sinh học (BOD) là lượng oxy cần thiết để phân giải các hợp chất hữu cơ dễ phân hủy



bởi vi sinh vật (Clesceri \& Franson, 1998). Trong khi đó, nhu cầu oxy hóa học (COD) là lượng oxy cần thiết để oxy hóa các hợp chất hóa học trong nước bao gồm cả vô cơ và hữu cơ. Như vậy, $\mathrm{COD}$ là lượng oxy cần để oxy hóa toàn bộ các chất hóa học trong nước. Do vậy, việc xác định nhu cầu oxy hóa học và oxy sinh học nhằm đánh giá chất lượng môi trường nước của thủy vực (Nollet \& De Gelder, 2000). Vì khi hai giá trị này cao trong nước sẽ làm giảm hàm lượng oxy hòa tan của nước, có hại cho sinh vật trong nước nói riêng và hệ sinh thái nói chung.

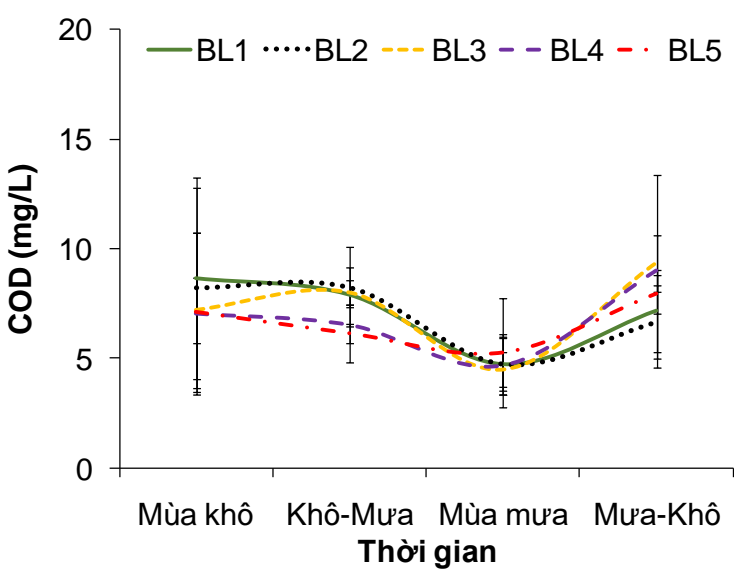

Hình 5. Hàm lượng $\mathrm{BOD}_{5}$ và $\mathrm{COD}$ qua thời gian thu mẫu

Kết quả ghi nhận hàm lượng $\mathrm{BOD}_{5}$ ở các điểm thu qua các mùa trong năm có giá trị trung bình thấp; giá trị trung bình dao động từ $2,2-5,1 \mathrm{mgO}_{2} / \mathrm{L}$. Giá trị $\mathrm{BOD}_{5}$ có $\mathrm{xu}$ hướng giảm vào thời điểm giao mùa khô-mưa và có xu hướng tăng cao vào mùa mưa và giao mùa mưa-khô ở các điểm thu. Vì vào mùa khô, lưu lượng nước sông từ nội đồng chảy ra kém nên lượng nước biển xâm nhập vào các vùng cửa sông nhiều hơn làm cho các thủy vực vùng cửa sông ít bị ô nhiễm. Vào mùa mưa hay giao mùa mưa khô, nước từ nội đồng đổ ra cửa biển nhiều hơn, kèm với đó là sự rửa trôi, xáo trộn nền đáy nên làm cho chất lượng nước giảm thấp. Trần Trung Giang và ctv. (2020) ghi nhận hàm lượng $\mathrm{BOD}_{5}$ có giá trị trung bình dao động 2,2-6,6 mgO $/ 2$ đối với các thủy vực vùng cửa sông tại khu vực nuôi tôm tỉnh Sóc Trăng. Theo nghiên cứu Green \& Ward (2011), hàm lượng $\mathrm{BOD}_{5}$ trong ao nuôi tôm thẻ $L$. vannamei có giá trị trung bình là 8,6 và $7,7 \mathrm{mgO}_{2} / \mathrm{L}$ vào mùa khô và mùa mưa, tương ứng. Đối với các kênh trong khu vực nuôi tôm tại Honduras, hàm lượng $\mathrm{BOD}_{5}$ có giá trị trung bình vào mùa khô là $2,8 \pm 1,0 \mathrm{mgO}_{2} / \mathrm{L}$ và vào mùa mưa là $7,5 \pm 2,6 \mathrm{mgO}_{2} / \mathrm{L}$. Boyd $\&$ Green (2002) đề nghị rằng giá trị $\mathrm{BOD}_{5}$ nên từ $5-6 \mathrm{mgO}_{2} / \mathrm{L}$ để đảm bảo chất lượng nguồn nước cho thủy vực, hệ sinh thái ven bờ. Theo quy chuẩn QCVN 08MT:2015/BTNMT, giá trị giới hạn chất lượng nước sử dụng cho mục đích cấp nước sinh hoạt (sau khi áp dụng xử lý thông thường), bảo tồn động thực vật thủy sinh và các mục đích khác là $4 \mathrm{mgO}_{2} / \mathrm{L}\left(\mathrm{A}_{1}\right)$ (Bộ Tài nguyên và Môi trường, 2015a). Như vậy, có thể thấy giá trị trung bình của $\mathrm{BOD}_{5}$ tại các điểm thu ở các cửa sông dọc tuyến đê biển khu vực nuôi tôm tỉnh Bạc Liêu có giá trị thấp và có thể dùng để phục vụ cho nuôi trồng thủy sản của vùng.

Quy chuẩn Việt Nam 08-MT:2015/BTNMT quy định giá trị giới hạn của $\mathrm{COD}$ trong chất lượng nước sử dụng cho mục đích cấp nước sinh hoạt (sau khi áp dụng xử lý thông thường), bảo tồn động thực vật thủy sinh và các mục đích khác là $10 \mathrm{mgO}_{2} / \mathrm{L}$ (Bộ Tài nguyên và Môi trường, 2015a). Kết quả nghiên cứu hiện tại ghi nhận hàm lượng $\mathrm{COD}$ có giá trị trung bình tại các điểm thu qua các mùa khá thấp; có giá trị trung bình dao động từ 4,5-9,3 $\mathrm{mgO}_{2} / \mathrm{L}$. Kết quả cũng ghi nhận hàm lượng COD ít biến động tại các điểm thu trong cùng thời gian thu mẫu. Biao \& Xiaorong (2004) nhận định hàm lượng COD 
trong các kênh dẫn cho các vùng nuôi tôm thâm canh ở miền Đông Trung Quốc có giá trị trung bình $4,72 \mathrm{mgO}_{2} / \mathrm{L}$. Trai et al. (2006) ghi nhận hàm lượng COD tại sông Cần Giờ, Thành phố Hồ Chí Minh có giá trị trung bình 14,7-58,9 mgO $\mathrm{mg}_{2} / \mathrm{L}$ tại các điểm thu mẫu. Các tác giả cũng đã nhận định do ảnh hưởng của việc nuôi tôm trong khu vực và ô nhiễm đô thị đã làm suy giảm chất lượng nước của vùng. Nghiên cứu của Trần Trung Giang và ctv. (2020) ghi nhận hàm lượng $\mathrm{COD}$ có giá trị trung bình là $5,5 \pm 0,6$ $\mathrm{mgO}_{2} / \mathrm{L}$ tại các điểm thu vùng cửa sông. So với kết quả nghiên cứu hiện tại, hàm lượng $\mathrm{COD}$ trong nước tại các vùng cửa sông qua các mùa tại khu vực nuôi tôm tỉnh Bạc Liêu còn khá thấp, đạt quy chuẩn trong nguồn nước tầng mặt và có thể cung cấp cho mục đích tưới tiêu, thủy lợi cũng như phục vụ cho nuôi trồng thủy sản của vùng.

\subsection{TAN và $\mathrm{NO}_{2}{ }^{-}$}

Tổng đạm ammonia là bao gồm dạng ion ammonium $\left(\mathrm{NH}_{4}{ }^{+}\right.$, nguồn dinh dưỡng thực vật hấp thụ) và ammoniac $\left(\mathrm{NH}_{3}\right.$, gây độc đối với động vật thủy sinh); trạng thái cân bằng của hai dạng này thay đổi tùy thuộc vào giá trị $\mathrm{pH}$, nhiệt độ và độ mặn của nước (Boyd \& Tucker, 1998). Kết quả ghi nhận hàm lượng tổng đạm ammonia (TAN) ở các điểm thu mẫu qua các mùa có giá trị trung bình rất thấp, nhỏ hơn $0,6 \mathrm{mg} / \mathrm{L}$. Kết quả cũng ghi nhận hàm lượng TAN có sự biến động lớn vào thời điểm giao mùa khô-mưa và giao mùa mưa-khô ở các điểm thu mẫu.

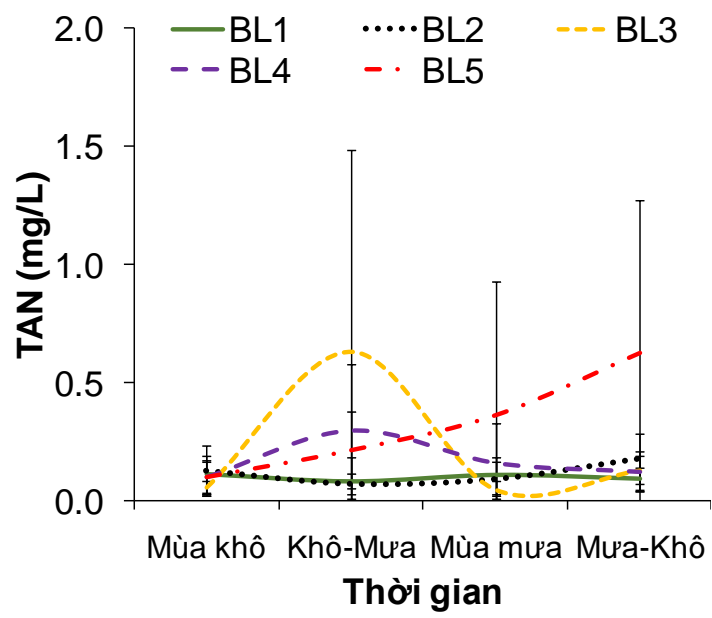

Tuy nhiên, giá trị trung bình vẫn còn ở mức thấp. Whetstone et al. (2002) cho rằng hàm lượng TAN trong nước dao động từ $0,2-2,0 \mathrm{mg} / \mathrm{L}$ sẽ đảm bảo tốt cho sự phát triển của tôm. Boyd \& Green (2002) cho rằng hàm lượng $\mathrm{TAN}$ là một trong những chỉ tiêu để đánh giá mức độ ô nhiễm của vùng nuôi tôm ven biển và hàm lượng phải nhỏ hơn hoặc bằng $3 \mathrm{mg} / \mathrm{L}$ thì đảm bảo cho hệ sinh thái ven bờ. Bui et al. (2012) nghiên cứu sự tác động của các ao nuôi tôm đối với chất lượng nước ở vùng ven biển Vịnh Hạ Long nhận định rằng hàm lượng TAN cao hơn trong các kênh liền kề với khu vực nuôi tôm, đặc biệt là sau vụ nuôi đã đang tác động tiêu cực đến chất lượng nước ở vùng ven biển vịnh Hạ Long. Trần Trung Giang và ctv. (2020) khi so sánh giữa hai loại hình thủy vực, hàm lượng TAN ở các thủy vực sông nội địa cao hơn các điểm thu ở vùng cửa sông, nhưng sự chênh lệch không cao qua 6 tháng đầu năm tại khu vực nuôi tôm tỉnh Sóc Trăng. Theo QCVN 08MT:2015/BTNMT, hàm lượng TAN cho phép ở tầng nước mặt là $0,3 \mathrm{mg} / \mathrm{L}\left(\mathrm{A}_{1}\right)$ (Bộ Tài nguyên và Môi trường, 2015a). Như vậy, với kết quả nghiên cứu hiện tại thì hàm lượng TAN tại các cửa sông khu vực nuôi tôm của tỉnh Bạc Liêu còn khá thấp. Mặc dù cửa sông là thủy vực luôn biến động, hơn nữa là chịu tác động từ các kênh dẫn từ nội đồng của các khu vực nuôi tôm nhưng hàm lượng TAN còn thấp và ít ảnh hưởng đến đời sống của động vật thủy sản nói riêng cũng như hệ sinh thái tầng nước mặt của vùng nói chung.



Hình 6. TAN và $\mathrm{NO}_{2}^{-}$qua thời gian thu mẫu

Kết quả ghi nhận hàm lượng $\mathrm{NO}_{2}^{-}$trong nước có $\mathrm{xu}$ hướng giảm qua các mùa thu mẫu. Hàm lượng $\mathrm{NO}_{2}{ }^{-}$có giá trị trung bình cao vào mùa khô trong năm và cao nhất tại điểm thu BL1 (Cửa sông Nhà Mát) với giá trị trung bình $0,19 \pm 0,08 \mathrm{mg} / \mathrm{L}$. Điều này là do sự tác động của ô nhiễm đô thị vì điểm thu là kênh dẫn từ trung tâm thành phố Bạc Liêu ra cửa sông Nhà Mát, kết hợp với lưu lượng kém vào mùa khô làm cho hàm lượng $\mathrm{NO}_{2}^{-}$trung bình tại điểm thu vào mùa khô có giá trị cao hơn so với các điểm thu còn lại. Hàm lượng $\mathrm{NO}_{2}{ }^{-}$trung bình dao động tại các điểm qua các mùa thu mẫu có giá trị từ $0,02-0,19$ 
$\mathrm{mg} / \mathrm{L}$. Hàm lượng $\mathrm{NO}_{2}^{-}$giảm dần qua các mùa thu mẫu và đến thời điểm giao mùa mưa khô có giá trị thấp chỉ còn $0,04 \pm 0,02 \mathrm{mg} / \mathrm{L}$ ở các điểm thu mẫu. Theo Tổ chức công tác về môi trường biển và ven biển (AWGCME, 2009), hàm lượng $\mathrm{NO}_{2}^{-}$khuyến cáo tại khu vực châu Á nên có giá trị nhỏ hơn 0,055 $\mathrm{mg} / \mathrm{L}$. Bui et al. (2012) khảo sát chất lượng nước ở các kênh dẫn tại vùng ven biển Vịnh Hạ Long thì hàm lượng $\mathrm{NO}_{2}{ }^{-}$ở mức từ $0,074-0,081 \mathrm{mg} / \mathrm{L}$ tại các điểm thu mẫu. Quy chuẩn Việt Nam 08MT:2015/BTNMT quy định giá trị giới hạn của $\mathrm{NO}_{2}^{-}$trong chất lượng nước sử dụng cho mục đích cấp nước sinh hoạt (sau khi áp dụng xử lý thông thường), bảo tồn động thực vật thủy sinh và các mục đích khác là $0,05 \mathrm{mg} / \mathrm{L}$ (Bộ Tài nguyên và Môi trường, 2015a). Như vậy có thể thấy rằng giá trị $\mathrm{NO}_{2}^{-}$trung bình tại các điểm thu mẫu qua các mùa của khu vực nuôi tôm tỉnh Bạc Liêu còn thấp, ít ảnh hưởng đến đời sống thủy sinh vật của vùng.

\section{6. $\mathrm{H}_{2} \mathrm{~S}$ và $\mathrm{PO}_{4}{ }^{3-}$}

Lưu huỳnh là một nguyên tố thiết yếu cho thực vật, động vật và vi khuẩn được tìm thấy trong nước tự nhiên và các ao nuôi trống thủy sản. Trong tự nhiên, có thể tìm thấy ở dạng đơn chất hay trong các khoáng chất sulfua và sulfat. Khí hydro sulfide $\left(\mathrm{H}_{2} \mathrm{~S}\right)$ là một trong những dạng tồn tại của lưu huỳnh trong nước, chúng được hình thành từ quá trình phân hủy mùn bã hữu cơ của vi khuẩn trong điều kiện yếm khí. Tuy nhiên, khí $\mathrm{H}_{2} \mathrm{~S}$ gây thiếu hụt oxy trong nước và gây độc đối với động vật thủy sản. Theo Boyd (1998), hàm lượng $\mathrm{H}_{2} \mathrm{~S}$ từ $0,01-0,05 \mathrm{mg} / \mathrm{L}$ có thể gây chết thủy sinh vật. Fast \& Boyd (1992) đề nghị rằng hàm lượng $\mathrm{H}_{2} \mathrm{~S}$ tốt nhất cho tôm sinh

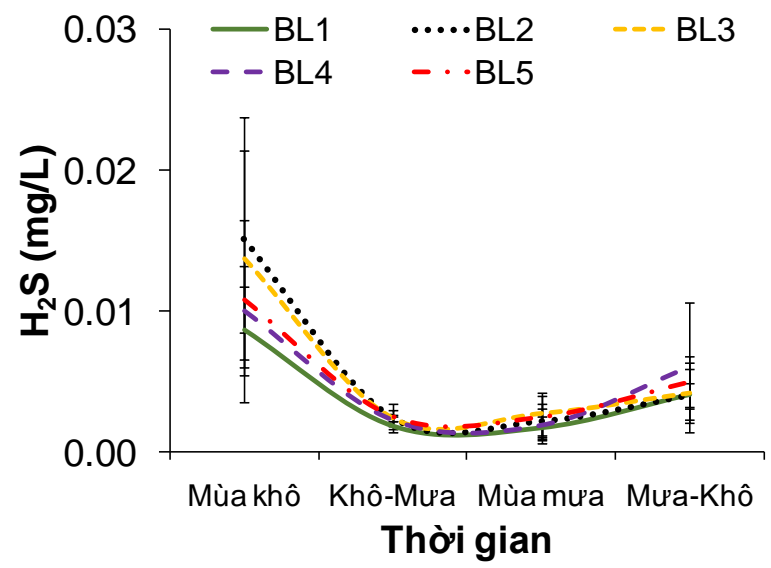

\section{Hình 7. Hàm lượng khí $\mathrm{H}_{2} \mathrm{~S}$ và $\mathrm{PO}_{4}{ }^{3-}$ qua thời gian thu mẫu}

Hàm lượng $\mathrm{PO}_{4}{ }^{3-}$ qua các mùa có sự biến động ở các điểm thu mẫu, tuy nhiên vẫn còn ở mức thấp. Hàm lượng $\mathrm{PO}_{4}{ }^{3-}$ có giá trị trung bình là $0,16 \pm 0,10$ trưởng và phát triển là không phát hiện trong nước. Chanratchakkol et al. (2003) cho rằng hàm lượng $\mathrm{H}_{2} \mathrm{~S}$ phù hợp cho ao tôm phải nhỏ hơn $0,03 \mathrm{mg} / \mathrm{L}$. Kết quả nghiên cứu của Phạm Thị Tuyết Ngân và Trương Quốc Phú (2010) ghi nhận được hàm lượng khí $\mathrm{H}_{2} \mathrm{~S}$ trong nước của các ao nuôi tôm sú thâm canh có giá trị dao động từ $0,009-0,031 \mathrm{mg} / \mathrm{L}$. Kết quả nghiên cứu hiện tại ghi nhận hàm lượng khí $\mathrm{H}_{2} \mathrm{~S}$ tại các cửa sông ven đê biển khu vực nuôi tôm Bạc Liêu có giá trị trung bình từ $0,002-0,015 \mathrm{mg} / \mathrm{L}$ qua thời gian thu mẫu. Hàm lượng $\mathrm{H}_{2} \mathrm{~S}$ được phát hiện cao nhất vào mùa khô với giá trị trung bình qua các điểm thu mẫu là $0,012 \pm 0,003 \mathrm{mg} / \mathrm{L}$ và giảm dần vào khoảng thời gian còn lại trong năm. Do đây là thủy vực tự nhiên và là vùng cửa sông nên hàm lượng khí $\mathrm{H}_{2} \mathrm{~S}$ tồn lưu trong nước kém. Kết quả ghi nhận hàm lượng khí $\mathrm{H}_{2} \mathrm{~S}$ trong nước vẫn còn rất thấp, ít ảnh hưởng đến đời sống của động vật thủy sản và hệ sinh thái của vùng. Theo báo cáo kết quả quan trắc chất lượng nước trên kênh cấp phục vụ vùng nuôi tôm nước lợ tập trung ở Đồng bằng sông Cửu Long của Viện Nghiên cứu Nuôi trồng Thủy sản II (2020), các điểm thu tại các sông Cái Đôi, Phú Tân và sông Hòa Mỹ, Cống Đá, Cái Nước tỉnh Cà Mau vào tháng 5 năm 2020 có giá trị trung bình là $0,017 \mathrm{mg} / \mathrm{L}$ và $0,011 \mathrm{mg} / \mathrm{L}$ tương ứng. Theo QCVN 0219:2014/BNNPTNT thì chất lượng nước cấp vào ao nuôi và nước ao nuôi tôm sú và tôm thẻ chân trắng phải có giá trị hàm lượng khí $\mathrm{H}_{2} \mathrm{~S}$ nhỏ hơn 0,05 $\mathrm{mg} / \mathrm{L}$ (Bộ Nông nghiệp và Phát triển nông thôn, 2014). Như vậy, với kết quả nghiên cứu hiện tại thì hàm lượng khí $\mathrm{H}_{2} \mathrm{~S}$ trong nước tại các điểm thu qua các mùa thu mẫu còn rất thấp so với các yêu cầu, quy chuẩn trong nuôi trồng thủy sản.

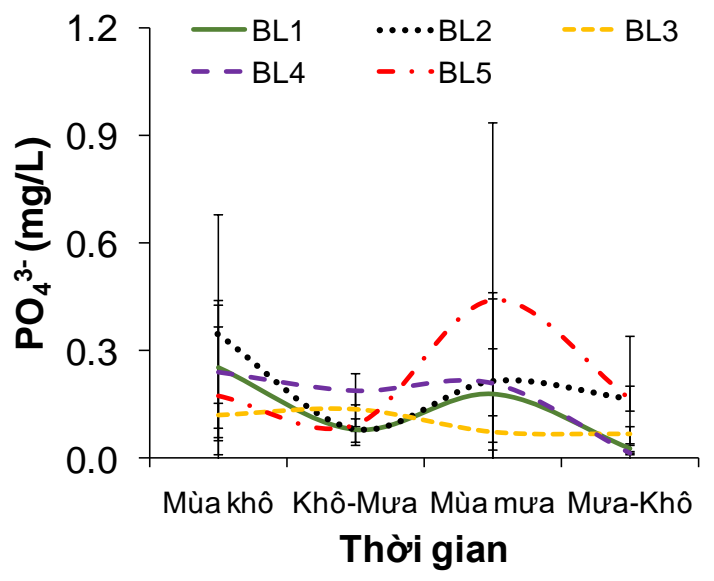

$\mathrm{mg} / \mathrm{L}$ ở các điểm thu mẫu. Hàm lượng $\mathrm{PO}_{4}{ }^{3-}$ có sự biến động ở các điểm thu mẫu vào mùa khô và mùa mưa, với giá trị trung bình là $0,23 \pm 0,09 \mathrm{mg} / \mathrm{L}$ và 
$0,22 \pm 0,13 \mathrm{mg} / \mathrm{L}$ tương ứng. Hai thời điểm giao mùa còn lại trong năm có giá trị $\mathrm{PO}_{4}{ }^{3-}$ trung bình thấp là $0,12 \pm 0,05 \mathrm{mg} / \mathrm{L}$ vào thời gian giao mùa khô-mưa và $0,09 \pm 0,07 \mathrm{mg} / \mathrm{L}$ vào thời gian giao mùa mưa-khô. Theo QCVN 08-MT:2015/BTNMT quy định giá trị giới hạn của hàm lượng $\mathrm{PO}_{4}{ }^{3-}$ trong chất lượng nước sử dụng cho mục đích cấp nước sinh hoạt (sau khi áp dụng xử lý thông thường), bảo tồn động thực vật thủy sinh và các mục đích khác trên tầng mặt có giá trị giới hạn là $0,1 \mathrm{mg} / \mathrm{L}$ (Bộ Tài nguyên và Môi trường, 2015a). Như vậy có thể thấy rằng hàm lượng $\mathrm{PO}_{4}{ }^{3-}$ tại các điểm thu qua thời gian thu mẫu có giá trị vượt giới hạn trung bình từ 1,0-2,3 lần. Do vậy cần lưu ý xử lý nguồn nước trước khi đưa vào trong ao nuôi. Theo kết quả quan trắc chất lượng nước trên kênh cấp phục vụ vùng nuôi tôm nước lợ tập trung ở đồng bằng sông Cửu Long của Viện Nghiên cứu Nuôi trồng Thủy sản II (2020), các điểm thu tại các kênh dẫn của khu vực nuôi tôm Bạc Liêu hàm lượng $\mathrm{PO}_{4}{ }^{3-}$ có giá trị trung bình là $0,27-0,54 \mathrm{mg} / \mathrm{L}$ vào tháng 4 và từ $0,081-0,146 \mathrm{mg} / \mathrm{L}$ vào tháng 5 năm 2020. Trần Trung Giang và ctv. (2020) nghiên cứu mẫu ở thủy vực vùng cửa sông khu vực nuôi tôm tỉnh Sóc Trăng kết luận hàm lượng $\mathrm{PO}_{4}{ }^{3-}$ có giá trị trung bình là $0,29 \pm 0,18 \mathrm{mg} / \mathrm{L}$ qua 6 tháng thu mẫu. Theo kết quả quan trắc môi trường chất lượng nước phục vụ vùng nuôi tôm nước lợ tỉnh Cà Mau của Tổng cục Thủy sản (2018), hàm lượng $\mathrm{PO}_{4}{ }^{3-}$ tại 4 điểm quan trắc gồm sông Đường Chéo, kênh xáng Độ Cường, sông Thị Tường và kênh xáng Tân Hưng có hàm lượng từ $0,5-2,88 \mathrm{mg} / \mathrm{L}$. Như vậy, có thể thấy rằng hàm lượng $\mathrm{PO}_{4}{ }^{3-}$ ở các cửa sông ven đê biển khu vực nuôi tôm của tỉnh Bạc Liêu còn rất thấp so với khu vực nuôi tôm khác trong vùng. Tuy nhiên khi sử dụng nguồn nước cần có những biện pháp xử lý cụ thể cho từng mục đích sử dụng.

\section{KẾT LUÂN}

Chất lượng nước tại khu vực nuôi tôm ven đê biển Bạc Liêu ít bị biến động, đạt yêu cầu theo các quy chuẩn về chất lượng nước tầng mặt, phù hợp đối với việc sử dụng nguồn nước phục vụ cho nhu cầu nuôi trồng thủy sản của vùng, đặc biệt là nghề nuôi tôm nước lợ. Hàm lượng $\mathrm{TSS}, \mathrm{H}_{2} \mathrm{~S}, \mathrm{PO}_{4}{ }^{3-}$ trong nước tại một số điểm thu khá cao so với quy chuẩn. Vì vậy cần có những biện pháp xử lý phù hợp trước khi đưa nguồn nước vào sử dụng.

Qua 5 điểm thu tại cửa sông ven đê biển Bạc Liêu, chất lượng nước tại điểm thu BL1 (cửa sông Nhà Mát $-\mathrm{TP}$. Bạc Liêu) và điểm thu BL5 (cửa sông Gành Hào - Đông Hải) rất dễ bị biến động do chịu sự ảnh hưởng của nước thải sinh hoạt cũng như nguồn nước từ khu vực nuôi tôm nội đồng đổ ra vùng cửa sông. Vào khoảng thời gian giao mùa mưa-khô và mùa khô, chất lượng nước tại các cửa sông có xu hướng kém hơn so với thời gian còn lại trong năm.

\section{LỜI CẢM TẠ}

Đề tài này được tài trợ bởi Dự án Nâng cấp Trường Đại học Cần Thơ VN14-P6 bằng nguồn vốn vay ODA từ Chính phủ Nhật Bản.

\section{TÀI LIỆU THAM KHẢO}

APHA, AWWA, WEF. (1995). Standard methods for the examination of water and wastewater, 19th Edition. American Public Health Association, Washington DC, 1108 pages.

AWGCME. (2009). The Marine Water Quality Criteria for the ASEAN Region. AWGCME.

Biao, X., Zhuhong, D., \& Xiaorong, W. (2004). Impact of the intensive shrimp farming on the water quality of the adjacent coastal creeks from Eastern China. Marine Pollution Bulletin, 48(56), 543-553.

Bộ Khoa học và Công nghệ. (2016). Tổng luận Xâm nhập mặn tại đồng bằng sông Củu Long: Nguyên nhân, tác động và các giải pháp úng phó.

Bộ Nông nghiệp và Phát triển Nông thôn. (2015). Báo cáo tồng hợp Quy hoạch nuôi tôm nước lợ vùng Đồng bằng sông Cưu Long đến năm 2020, tầm nhìn 2030.

Bộ Tài nguyên và Môi trường. (2011). QCVN 38:2011/BTNMT. Quy chuẩn kỹ thuật quốc gia về chất luợng nước mặt bảo vệ đời sống thủy sinh.

Bộ Tài nguyên và Môi trường. (2014). QCVN 0219:2014/BNNPTNT. Quy chuẩn kỹ thuật quốc gia về cơ sở nuôi tôm nước lợ - điều kiện bảo đảm vệ sinh thú $y$, bảo vệ môi trường và an toàn thực phẩm.

Bộ Tài nguyên và Môi trường (2015a). QCVN 08MT: 2015/BTNMT. Quy chuẩn kỹ thuật quốc gia về chất lương nước mặt.

Bộ Tài nguyên và Môi trường (2015b). QCVN 10MT:2015/BTNMT. Quy chuẩn kỹ thuật quốc gia về chất luợng nước biển.

Boyd, C. E. (1998). Water quality for pond aquaculture. Research and development series, No.43, 37 pages.

Boyd, C. E., \& Green, B. W. (2002). Water quality monitoring in shrimp farming areas: an example from Honduras, Shrimp Farming and the Environment. Report prepared under the World Bank, NACA, WWF and FAO Consortium Program on Shrimp Farming and the Environment, Auburn, USA, 29 pages. 
Boyd, C. E., \& Tucker, C. S. (1998). Pond Aquaculture Water Quality Management. Boston, Kluwer Academic, London.

Chanratchakool, P., Turnbull, J. F., Funge-Smith, S. J., Macrae, I. H., \& Limsuwan, C. (2003). Quản lý súc khỏe tôm trong ao nuôi. Tái bản lần thư 4. Người dịch: Nguyê̂n Anh Tuấn, Nguyễn Thanh Phưong, Đặng Thị Hoàng Oanh, Trần Ngọc Hải. Danida-Bộ Thủy sản, 2003.

Clesceri, L. S., \& Franson, M. A. H. (1998). Standard Methods for the Examination of Water and Wastewater. 20th Edn., American Public Health Association, Washington D.C.

Fast, A. W., \& Boyd, C. E. (1992). Water circulation, aeration and other management practices. Developments in aquaculture and fisheries science, 23, 457-495.

Green, B., \& Ward, G. H. (2011). Ultimate biochemical oxygen demand in semi-intensively managed shrimp pond waters. Aquaculture, 319(1-2), 253-261.

Nguyễn Kỳ Phùng, Nguyễn, Thái Sơn, Trần Tuấn Hoàng \& Nguyễn Đình Tuấn. (2016). Tính toán và dự báo xâm nhập mặn tại tỉnh Bạc Liêu theo kịch bản biến đổi khí hậu. Tạp chí Khí tuợng Thủy văn, 661, 24-28.

Trai, N. V., Momtaz, S., \& Zimmerman, K. (2006). Water pollution concerns in shrimp farming in Vietnam: A case study of Can Gio, Ho Chi Minh City. The International Journal of Environmental, Cultural, Economic and Social Sustainability, 3(2), 129-138.

Nollet, L. M., \& De Gelder, L. S. (Eds.). (2000). Handbook of water analysis. CRC press.

Phạm Thị Tuyết Ngân \& Trương Quốc Phú (2010). Biến động các yếu tố môi trường trong ao nuôi tôm sú (Penaeus monodon) thâm canh tại Sóc Trăng. Tạp chi Khoa hoc Truòng Đại học Cần Tho, 15a, 179-188.

Sở Nông nghiệp và Phát triển nông thôn tỉnh Bạc Liêu. (2019). Hội nghị Tổng kết sản xuất thủy sản năm 2019, triển khai nhiệm vụ, giải pháp năm 2020. Ngày 03/10/2019. http//www.snnptnt@baclieu.gov.vn.

Bui, T. D., Luong-Van, J., \& Austin, C. M. (2012). Impact of shrimp farm effluent on water quality in coastal areas of the world heritage-listed Ha Long Bay. American Journal of Environmental Sciences, 8(2), 104-116.

Tổng cục Thủy sản. (2018). Kết quả quan trắc môi truò̀ng chất luợng nước phục vu vùng nuôi tôm nước lợ tỉnh Cà Mau. Tổng cục Thủy sản, Nuôi trồng thủy sản, Quản lý môi trường.

Tổng cục Thủy sản. (2019). Kết quả quan trắc môi truờng tại các huyện trọng điểm nuôi tôm tỉnh Sóc Trăng trong tháng 5/2019. Tổng cục Thủy sản, Nuôi trồng thủy sản, Quản lý môi trường.

Trai, N, V. (2008). The influences of shrimp farming and fishing practices on natural fish conservation in Can Gio, Ho Chi Minh City, Vietnam (Ph.D. Dissertation). University of Newcastle.

Trần Trung Giang, Aina Ayotunde Oluwadamilare, Âu Văn Hóa, Huỳnh Trường Giang, Trương Quốc Phú, Minoru Wada \& Vũ Ngọc Út. (2020). Đánh giá chất lượng nước trong khu vực nuôi tôm tỉnh Sóc Trăng. Tạp chí Khoa hoc Truờng Đại học Cần Tho. 56(Số chuyên đề Thủy sản), 112-120.

Trung tâm khuyến nông tỉnh Bạc Liêu. (2020). Bạc Liêu nuôi tôm thích ưng với biến đổi khi hậu. http://cdc.org.vn/cong-thong-tin/bien-doi-khihau/bac-lieu-nuoi-tom-thich-ung-voi-bien-doikhi-hau-3098.html

Venkateswarlu, V., Seshaiah, P. V., Arun, P. \& Behra, P. C. (2019). A study on water quality parameters in shrimp L. vannamei semi-intensive grow out culture farms in coastal districts of Andhra Pradesh, India. International Journal of Fisheries and Aquatic Studies - IJFAS, 7, 394-399.

Viện Khoa học Thủy lợi. (2013). Dự báo xâm nhập mặn tại các cứa sông vùng ven biển đồng bằng sông Cưu Long và Đề xuất các giải pháp chống hạn.

Viện Nghiên cứu Nuôi Trồng Thủy sản II. (2020). Kết quả quan trắc chất lương nước phục vu vùng nuôi tôm nước lợ tập trung ở Đồng bằng sông Cứu Long. Số 36/TTQT-ĐT và 58/TTQT-ĐT.

Whetstone, J. M., Treece, G. D., Browdy, C. L. \& Stokes, A. D. (2002). Opportunities and constraints in marine shrimp farming. Southern Regional Aquaculture Center Publication, No 2600, 1-8. 